\title{
Parliamentary privilege-mortality in members of the Houses of Parliament compared with the UK general population: retrospective cohort analysis, 1945-2011
}

\author{
(C) $(1)(9)$ OPEN ACCESS
}

\author{
John Dennis $P h D$ student ${ }^{12}$, Tim Crayford chief medical advisor ${ }^{2}$ \\ 'University of Exeter Medical School, Exeter EX1 2LU, UK; ${ }^{2}$ Just Retirement, Vale House, Reigate, Surrey, UK
}

\begin{abstract}
Objective To examine mortality in members of the two UK Houses of Parliament compared with the general population, 1945-2011.

Design Retrospective cohort analysis of death rates and predictors of mortality in Members of Parliament (MPs) and members of the House of Lords (Lords).

Setting UK.

Participants 4950 MPs and Lords first joining the UK parliament in 1945-2011.

Main outcome measure Standardised mortality ratios, comparing all cause death rates of MPs and Lords from first election or appointment with those in the age, sex, and calendar year matched general population.

Results Between 1945 and 2011, mortality was lower in MPs (standardised mortality ratio $0.72,95 \%$ confidence interval 0.67 to 0.76 ) and Lords $(0.63,0.60$ to 0.67$)$ than in the general population. Over the same period, death rates among MPs also improved more quickly than in the general population. For every 100 expected deaths, 22 fewer deaths occurred among MPs first elected in 1990-99 compared with MPs first elected in 1945-49. Labour party MPs had 19\% higher death rates compared with the general population than did Conservative MPs (relative mortality ratio $1.19,95 \%$ confidence interval 1.01 to 1.40 ). The effect of political party on mortality disappeared when controlling for education level.

Conclusions From 1945 to 2011, MPs and Lords experienced lower mortality than the UK general population, and, at least until 1999, the mortality gap between newly elected MPs and the general population widened. Even among MPs, educational background was an important predictor of mortality, and education possibly explains much of the mortality difference between Labour and Conservative MPs. Social inequalities are alive and well in UK parliamentarians, and at least in terms of mortality, MPs are likely to have never had it so good.
\end{abstract}

\section{Introduction}

Are members of the House of Commons (MPs) and the House of Lords (Lords) similar to other UK citizens (box)? To answer this, we examined the simple and fundamental measure of mortality. The only published study that has examined this point is almost 50 years old, and it established that in 1945-67 MPs had lower death rates than those of the general population, but that mortality did not differ by political party. ${ }^{1}$ It did not consider the Lords. Anecdotal evidence suggests that the working environment and lifestyle of MPs has negative consequences on cardiovascular illness. ${ }^{2}$ Another study found that Dutch parliamentarians had similar death rates to the general population.

We examined the death rates of MPs and Lords compared with the UK general population in 1945-2011. We also searched for predictors of mortality among MPs. Measuring relative mortality allowed death rates in MPs and Lords from the year they joined parliament to be compared with those in the UK population matched for age, sex, and calendar year. This enabled mortality to be examined while controlling for the considerable improvements in death rates at almost all ages experienced in the population since 1945 .

\section{Methods \\ Data sources}

From UK parliament data we extracted biographical data on MPs and Lords in parliament from 1979 to $2011 .^{4}$ The parliamentary archive of MPs ${ }^{5}$ (1945-2006 only), the UK peerage database, ${ }^{6}$ and the peerages of the UK database, ${ }^{7}$ provided further information from multiple sources, including Who's Who, biographies, and newspapers. 


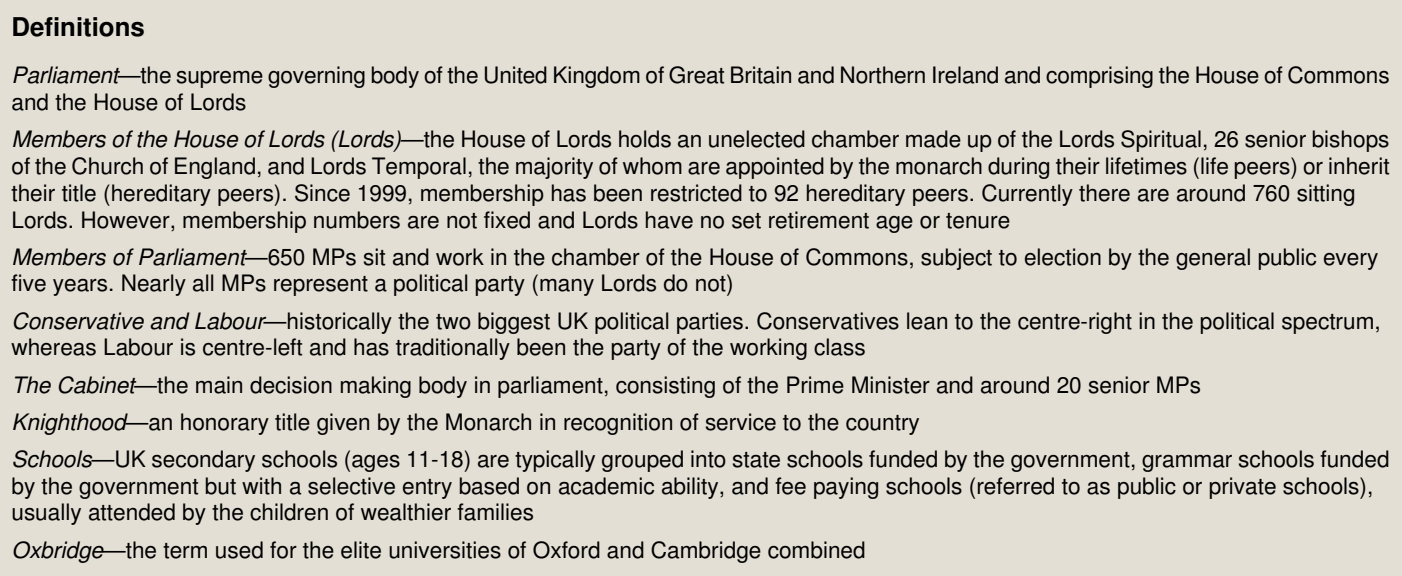

We cross referenced sources to determine members' dates of birth, election or appointment, and, if applicable, death, sex, and party affiliation. For MPs we compiled information on education, time in parliament, Cabinet appointments, and knighthoods. ${ }^{5}$ We obtained further data on year of appointment to the Cabinet or knighthood from similar sources to the parliamentary archive of MPs.

\section{Procedures}

MPs and Lords first elected or appointed from 1945 to 2011 were eligible. Follow-up began on the date a member first joined parliament and ended at death or 31 December 2011. We censored MPs who later became Lords as MPs on the date they became Lords, and they were included as Lords from that date onwards.

We compared the observed mortality in members with the expected mortality of the general population, matched to the same sex or age of the member in the year of entry to parliament. For each member we derived the expected lifetime, conditional on survival until entry into the study, from general population life tables. ${ }^{8}$ Conditioning prevents immortal time bias. ${ }^{9} 10$ The "strs" command ${ }^{11}$ in Stata V13 was used to derive expected deaths and person years at risk for MPs and Lords separately, overall, and stratified by calendar period of election or appointment. We used Poisson generalised linear models with expected deaths as the offset to estimate relative mortality, interpretable as standardised mortality ratios and relative mortality ratios, as previously applied to study mortality in type 2 diabetes. ${ }^{12}$ Time since entry was the timescale. We examined the relative mortality time trend over the study for MPs and Lords separately by including year of election or appointment as a linear term in additional models. In MPs we studied relative mortality by political party. MPs were categorised as Conservative, Labour, or other (MPs of all other parties). MPs who crossed the floor were classified by original party of allegiance.

Further predictors of mortality among Labour and Conservative MPs were investigated in those first elected in 1945-2006, for whom we had additional information. ${ }^{5}$ Small numbers precluded investigation of MPs from other parties. Highest recorded education level was defined as "secondary" if an MP did not attend university or had a schooling record only, and within the secondary category as "grammar or public" if they attended either type of school or "state or unknown" if they attended a state school or other institution or did not attend university and had a missing schooling record. The two other categories comprised MPs who attended university, grouped as "Oxbridge" if they attended Oxford or Cambridge, otherwise "other." We tested the sensitivity of this categorisation for missing data (see supplementary appendix 6).

We compared relative mortality in MPs with a Cabinet appointment or knighthood with other MPs, avoiding immortal time bias by beginning follow-up at the year of appointment or knighthood. To examine whether length of service was protective, while removing the possibility of immortal time bias, we compared mortality in those serving 20 years or more $(n=1199)$, starting observed time at the 20th year after election. In two multivariable regression models we then examined the association between relative mortality and sex, age at election, calendar period of election, and political party, with and without adjustment for education.

\section{Results}

The median follow-up for MPs and Lords was 19 years, and 359 MPs became Lords (table $1 \Downarrow$ ).

\section{Mortality of Lords and MPs (1945-2011)}

The death rates of MPs were $28 \%$ lower than those of the general population (standardised mortality ratio $0.72,95 \%$ confidence interval 0.67 to 0.76 ). Lords experienced $37 \%$ lower relative mortality $(0.63,0.60$ to 0.67$)$ (see supplementary appendix 1 ). The mortality of MPs who later became Lords was similar to that of other Lords (relative mortality ratio $1.02,95 \%$ confidence interval 0.87 to 1.20 ).

\section{Relative mortality over time (1945-2011)}

Relative mortality decreased by $39 \%$ among Lords, a decrease in standardised mortality ratio from 0.67 (0.56 to 0.79$)$ to 0.41 ( 0.25 to 0.67 ) (fig $1 \Downarrow$, see supplementary appendix 2 ), although the linear time trend by year of appointment was not significant $(\mathrm{P}=0.17)$. Mortality for MPs first elected in 2000-11 was similar to that of the general population (standardised mortality ratio $0.61,0.26$ to 1.47 ), although only five deaths occurred. From 1945 to 1999 relative mortality decreased by $28 \%$ among MPs, a decrease in standardised mortality ratio from 0.79 ( 0.70 to 0.89 ) to 0.57 ( 0.37 to 0.88 ) (fig $1 \Downarrow$, see supplementary appendix 2). From 1945 to 2011 overall, the linear time trend by year of election was significant for MPs $(\mathrm{P}<0.05)$.

\section{Characteristics of MPs by party (1945-2011)}

Table $2 \Downarrow$ shows the characteristics of MPs by political party. Male Conservative MPs had a higher median age at death compared with Labour MPs and MPs from other political parties. 


\section{Mortality in MPs by political party (1945-2011)}

MPs of all parties experienced lower death rates than the general population, and Conservative MPs had the lowest death rates (table $3 \Downarrow$ ). Relative mortality in Conservatives first elected in 1980-2011 was $24 \%$ lower than in Conservatives first elected in 1945-79; however, relative mortality was similar for Labour MPs across these periods (see supplementary appendix 3).

\section{Social background and career of Conservative and Labour MPs (1945-2006)}

Conservative MPs ( $\mathrm{n}=965)$ were more likely than Labour MPs $(n=1148)$ to attend Oxbridge, and if they did not attend university were more likely to have attended grammar or public school (fig $2 \Downarrow$ ). A higher proportion of Conservative than Labour MPs were knighted $(23 \% v 3 \%)$ and attained a Cabinet appointment $(8.8 \% \vee 7.5 \%)$ (see supplementary appendix 4$)$.

\section{Predictors of mortality in Conservative and Labour MPs}

The mortality of MPs with a Cabinet appointment or knighthood was similar to that of other MPs: respective relative mortality ratios 0.79 (0.56 to 1.10$)$ and 0.97 (0.80 to 1.18$)$. MPs who served for 20 years or more had lower mortality than those who served for less $(0.74,0.63$ to 0.87$)$. In a univariate model, compared with MPs categorised as having state or unknown education, mortality was reduced for those educated at grammar or public schools $(0.80,0.65$ to 0.97$)$ and Oxbridge $(0.73,0.61$ to 0.97$)$, but not for other universities $(0.86,0.71$ to 1.04$)$. Data were insufficient to analyse the effect of floating duck houses on mortality ( $\mathrm{n}=1$ known), although it was observed that Sir Peter Viggers, who infamously claimed for his personal duck island on parliamentary expenses, was still alive at the time of writing. ${ }^{13}$

In the multivariable model excluding education, the relative mortality of Labour MPs was $18 \%$ higher than that of Conservative MPs $(1.18,1.01$ to 1.37 ) (see supplementary appendix 5). However, when education was included, the mortality of Labour MPs was similar to that of Conservatives $(1.05,0.89$ to 1.25$)$, whereas the association between education and mortality remained (table $4 \Downarrow$ ). We found no difference in mortality by sex (the model accounts for underlying sex differences in the population), but lower mortality in MPs first elected at age 60 or more.

\section{Discussion}

During 1945 to 1999 , the UK population experienced considerable improvements in death rates. At the same time, death rates among Lords remained consistently lower than those of the general population. Mortality among MPs, however, decreased even more quickly. Much of the difference between MPs can be explained not by political party but rather by education.

Conservatives had the lowest death rates of all MPs. This party difference may be explained by MPs' social background, as measured by education. The relative death rates of MPs of either party who attended Oxbridge were reduced by $29 \%$ compared with those of MPs not educated beyond state school. MPs first elected at age 60 or more had lower relative mortality than MPs who were elected when younger. This may reflect a selection effect among MPs who were older at entry to parliament, by virtue of the fact they were fitter for office at that older age. Long serving MPs went on to live longer lives than other MPs.
Current and aspiring national politicians may do well to note a hitherto unforeseen benefit of seeking a safe parliamentary seat.

\section{Strengths and weaknesses}

This is the only study examining the mortality of both MPs and Lords, cross referencing multiple sources. Our statistical approach allowed unbiased measurement of the relative death rates of parliamentarians. However, a selection effect may partially explain the mortality differences, as parliamentarians would be expected to be healthier than the general population at election or appointment. Mortality differences therefore reflect lifetime social inequalities as well as health gains accrued in parliament.

A limitation of this study is the completeness of education data (see supplementary appendix 4). However, university attendance, the primary measure used to differentiate MPs, was complete for $95 \%$, and similar differences by party have been reported elsewhere. ${ }^{14-16}$ Sensitivity analyses support a true difference in education by political party (see supplementary appendix 6).

In keeping with our findings the only previous study found death rates in MPs in 1945-67 to be 20\% lower than those in the general population. ${ }^{1} \mathrm{~W}$ ith greater follow-up in the current study, we have shown a clear mortality difference by political party.

\section{Conclusion}

From 1945 to 2011, MPs and Lords experienced lower mortality than the UK general population. Furthermore, the mortality gap for MPs widened from 1945 to 1999, suggesting that over this period MPs may have become less representative of the population they serve. We are unable to draw meaningful conclusions in more recent MPs, as so few elected after 2000 are yet deceased. The fall in death rates among MPs may reflect improvements in lifestyle or working conditions, or perhaps that latter day MPs reap greater long term economic benefit from their time in parliament. Even among MPs—a narrow stratum of UK society - we found education to be an important predictor of mortality, and education possibly explains much of the mortality difference between Conservative and Labour MPs. Social inequalities are alive and well in UK parliamentarians, and at least in terms of mortality, MPs are likely to have never had it so good.

We thank Michael Rush (University of Exeter) for permitting the use of his parliamentary archive of UK MPs; Emma Peplow (History of Parliament Trust) for providing access to the data; David Beamish for access to the UK peerage creations 1801 to 2015 database; Leigh Rayment for access to the peerages of England, Scotland, Ireland, Great Britain and the United Kingdom database; and Richard Cracknell (House of Commons library) for his advice on data sources.

Competing interests: All authors have completed the ICMJE uniform disclosure form at www.icmje.org/coi_disclosure.pdf and declare: no support from any organisation for the submitted work; no financial relationships with any organisations that might have an interest in the submitted work in the previous three years; no other relationships or activities that could appear to have influenced the submitted work. Contributors: JD and TC contributed equally to the design and are guarantors. JD acquired, cleaned, analysed and interpreted the data and drafted the manuscript. TC had the original idea for the study and reviewed the analysis and manuscript. Both authors declare that they had full access to all of the data in the study, can take responsibility for the integrity of the data and the accuracy of the data analysis, and controlled the decision to publish.

Funding: This study received no specific funding 


\section{What is already known on this topic}

The mortality of UK MPs has not been examined since 1969, when Pincherle reported that MPs had lower death rates than the general population in 1945-67

No previous study has examined the mortality of members of the House of Lords

\section{What this study adds}

Mortality among MPs and Lords was, respectively, 28\% and 37\% lower than that of the general population in 1945-2011

The mortality gap between MPs and the general population has widened significantly over time

Mortality among Conservative MPs is lower than in MPs from other political parties, and this may reflect underlying differences in social background, as measured in this study by education

Ethical approval: Not required.

Data sharing: No additional data available.

Transparency: The authors affirm that this manuscript is an honest, accurate, and transparent account of the study being reported and that no aspects have been omitted.

1 Pincherle G. Mortality of members of Parliament [PubMed]. Br J Prev Soc Med 1969;23: 72-6. 5768140

2 Warden J. Letter from Westminster: killer in the house? BMJ 1989;298: 909-14.

3 Noteboom WM, Rosendaal FR, Vandenbroucke JP. [150 years of life expectancy of Dutch members of parliament; 1848-1989]. Ned Tijdschr Geneeskd 1991;135: 2425-8. 1758503

4 UK Parliament-members' names data platform. 2015. http://data.parliament.uk membersdataplatform/. UK Parliament contains parliamentary information licensed under the Open Parliament Licence v3.0 www.parliament.uk/site-information/copyright/openparliament-licence/

Rush M. Parliamentary archive of UK MPs. 2015

6 Beamish D. United Kingdom peerage creations 1801 to 2015 database. www.peerages. info/index.htm.

7 Rayment L. The peerages of England, Scotland, Ireland, Great Britain and the United Kingdom database. 2015. www.leighrayment.com/peers.htm.

8 Human mortality database. University of California BU, and Max Planck Institute for Demographic Research (Germany). 2015. www.mortality.org

9 Sylvestre M-P, Huszti E, Hanley JA. Do OSCAR winners live longer than less successfu peers? A reanalysis of the evidence. Ann Intern Med 2006;145: 361-3, discussion 392. doi:10.7326/0003-4819-145-5-200609050-00009 16954361
10 Lévesque LE, Hanley JA, Kezouh A, Suissa S. Problem of immortal time bias in cohort studies: example using statins for preventing progression of diabetes. $B M J$ 2010;340: b5087. doi:10.1136/bmj.b5087 20228141

11 Dickman PW, Coviello E. Estimating and modeling relative survival. Stata $J$ 2015;15: 186-215.

12 Gulliford MC, Charlton J. Is relative mortality of type 2 diabetes mellitus decreasing? Am J Epidemiol 2009:169: 455-61. doi:10.1093/aje/kwn342 19037005

13 Allen N. MPs' expenses: Sir Peter Viggers claimed for $£ 1,600$ floating duck island. Telegraph. 2009. www.telegraph.co.uk/news/newstopics/mps-expenses/5357568/MPsexpenses-Sir-Peter-Viggers-claimed-for-1600-floating-duck-island.html.

14 The educational backgrounds of Members of the House of Commons and House of Lords. Sutton Trust. 2005. www.suttontrust.com/wp-content/uploads/2005/12/ PoliticiansBackgrounds 09-Dec-05.pdf.

15 The educational backgrounds of Members of Parliament in 2010. Sutton Trust. 2010. www.suttontrust.com/wp-content/uploads/2010/05/1MPs_educational_backgrounds_ 2010_A.pdf.

16 Elitist Britain? Social Mobility and Child Poverty Commission. 2014. www.gov.uk government/uploads/system/uploads/attachment_data/file/347915/Elitist_Britain___Final. pdf.

\section{Accepted: 01122015}

Published by the BMJ Publishing Group Limited. For permission to use (where not already granted under a licence) please go to http://group.bmj.com/group/rights-licensing/ permissions

This is an Open Access article distributed in accordance with the Creative Commons Attribution Non Commercial (CC BY-NC 3.0) license, which permits others to distribute, remix, adapt, build upon this work non-commercially, and license their derivative works on different terms, provided the original work is properly cited and the use is non-commercial. See: http://creativecommons.org/licenses/by-nc/3.0/. 


\section{Tables}

Table 1| Characteristics of MPs and Lords (first elected 1945-2011). Values are numbers (percentages) unless specified otherwise

\begin{tabular}{lcc} 
Characteristics & MPs ( $\mathbf{n = 2 6 9 5 )}$ & Lords ( $\mathbf{n = 2 6 1 4 )}$ \\
\hline Median (interquartile range) age at joining parliament (years) & $42(37-48)$ & $58(47-64)$ \\
\hline Median (interquartile range) year of election or appointment & $1978(1959-97)$ & $1983(1966-97)$ \\
\hline Men & $2366(88)$ & $2348(90)$ \\
\hline Deaths & $937(35)$ & $1270(49)$ \\
\hline Median (interquartile range) age at death (years) & $75(66-83)$ & $80(72-86)$ \\
\hline Median (interquartile range) length of service (years) & $14(6-20)$ & $17(9-29)$ \\
\hline Median (interquartile range) duration of follow-up (years) & $20(11-33)$ & $17(10-28)$ \\
\hline Lords with history as MP & Not applicable & $359(14)$ \\
\hline Political party & & \\
\hline Conservative & $1138(42)$ & $662(30)$ \\
\hline Labour & $1231(46)$ & $385(17)$ \\
\hline Other & $326(12)$ & $642(29)$ \\
\hline Crossbench (Lords only) & Not applicable & $526(24)$ \\
\hline
\end{tabular}


Table 2| Characteristics of MPs first elected in 1945-2011, by political party. Values are medians (interquartile ranges) unless specified otherwise

\begin{tabular}{lccc} 
Characteristics & Conservative $(\mathbf{n = 1 1 3 8})$ & Labour $(\mathbf{n = 1 2 3 1})$ & Other $(\mathbf{n}=\mathbf{3 2 6})$ \\
\hline Age at election (years) & $40(36-46)$ & $43(38-50)$ & $43(35-50)$ \\
\hline Year of entry & $1977(1959-92)$ & $1974(1955-97)$ & $1986(1966-2001)$ \\
\hline No (\%) of men & $1052(92)$ & $1024(83)$ & $290(89)$ \\
\hline No (\%) of deaths & $384(34)$ & $462(38)$ & $91(28)$ \\
\hline Age of men at death & $75(67-83)$ & $74(64-82)$ & $74(68-82)$ \\
\hline Age of women at death & $78(66-90)$ & $78(69-87)$ & $\leq 5$ deaths \\
\hline Length of service (years) & $14(6-22)$ & $14(8-21)$ & $10(5-16)$ \\
\hline Follow-up (years) & $25(12-33)$ & $20(13-30)$ & $15(10-30)$ \\
\hline
\end{tabular}


Table 3| Deaths in MPs relative to general population by political party (1945-2011)

Party No Deaths Person years at risk Standardised mortality ratio $(95 \% \mathrm{Cl})$

$\begin{array}{llll}\text { Conservative } 1138 & 384 & 27004 & 0.66 \text { (0.60 to } 0.73)\end{array}$

\begin{tabular}{lllll}
\hline Labour & 1231 & 462 & 26464 & $0.76(0.70$ to 0.84$)$
\end{tabular}

\begin{tabular}{lllll}
\hline Other & 326 & 91 & 6602 & $0.76(0.62$ to 0.93$)$
\end{tabular}


Table 4| Multivariable regression model of relative mortality

\begin{tabular}{|c|c|}
\hline Political party & Standardised mortality ratio $(95 \% \mathrm{Cl})$ \\
\hline Conservative & 1 (ref) \\
\hline Labour & 1.05 (0.89 to 1.25$)$ \\
\hline \multicolumn{2}{|l|}{ Highest education level } \\
\hline Secondary: state or unknown & 1 (ref) \\
\hline Secondary: grammar or public & 0.80 (0.64 to 0.99$)$ \\
\hline University: other & $0.82(0.67$ to 1.01$)$ \\
\hline University: Oxbridge & 0.71 (0.57 to 0.87$)$ \\
\hline \multicolumn{2}{|l|}{ Sex } \\
\hline Women & $1.01(0.71$ to 1.44$)$ \\
\hline Men & 1 (ref) \\
\hline \multicolumn{2}{|l|}{ Period of election } \\
\hline $1945-49$ & $1.15(0.91$ to 1.44$)$ \\
\hline $1950-59$ & $1.10(0.88$ to 1.36$)$ \\
\hline $1960-69$ & $0.92(0.72$ to 1.18$)$ \\
\hline $1970-79$ & 1 (ref) \\
\hline $1980-89$ & $0.91(0.61$ to 1.37$)$ \\
\hline $1990-99$ & $0.98(0.60$ to 1.60$)$ \\
\hline $2000-11$ & $0.84(0.21$ to 3.41$)$ \\
\hline \multicolumn{2}{|l|}{ Age group at election (years) } \\
\hline $0-29.9$ & $1.21(0.76$ to 1.93$)$ \\
\hline $30-39.9$ & 0.91 (0.76 to 1.09$)$ \\
\hline $40-49.9$ & 1 (ref) \\
\hline $50-59.9$ & $0.92(0.77$ to 1.10$)$ \\
\hline$\geq 60$ & 0.66 (0.47 to 0.92$)$ \\
\hline
\end{tabular}




\section{Figures}

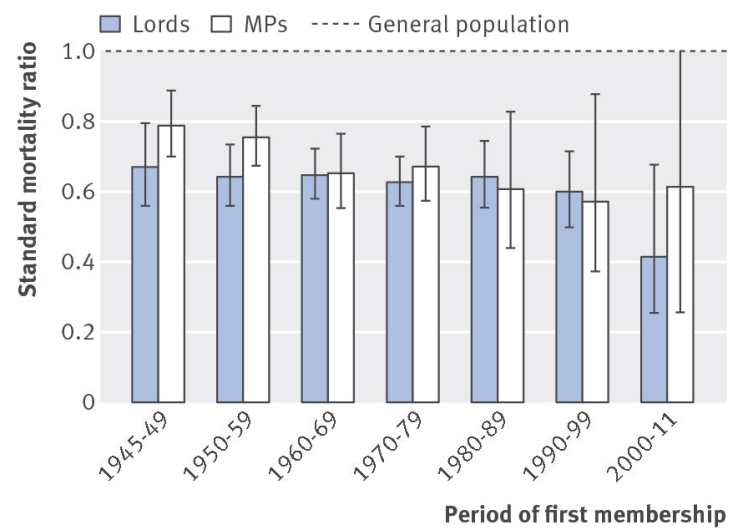

Fig 1 Standardised mortality ratios for MPs and Lords compared with UK general population, by period of first election

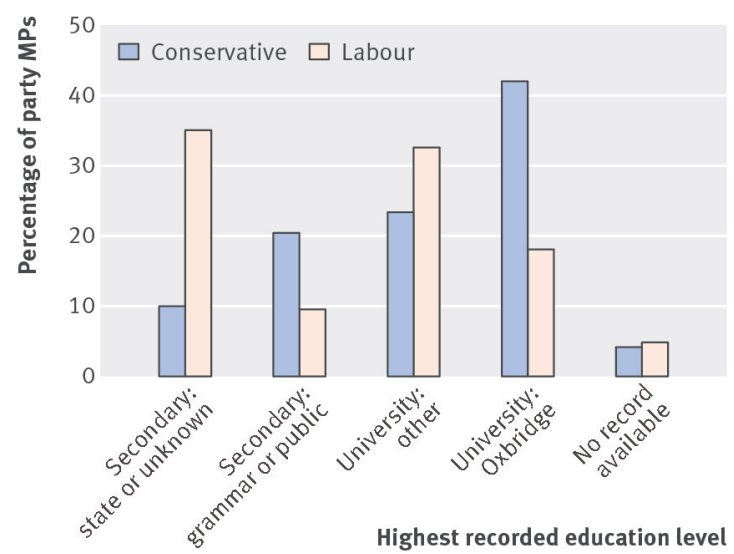

Fig 2 Highest recorded education level in Conservative and Labour MPs first elected 1945-2006 